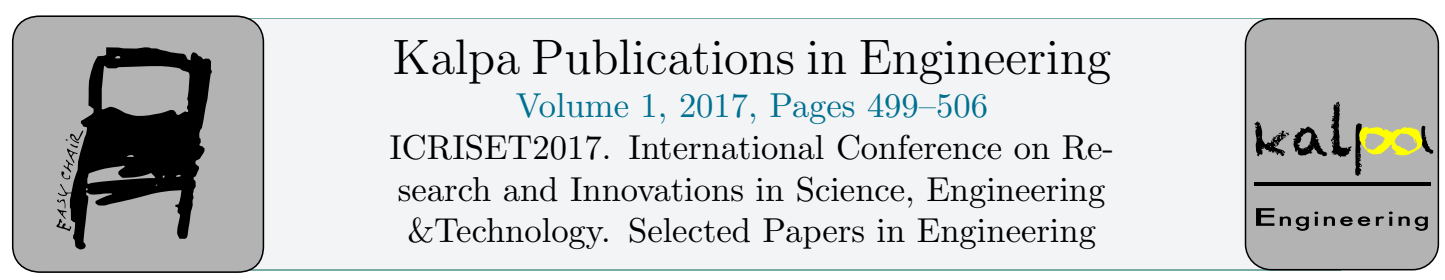

\title{
The Features of Metal-Forming Processes Modeling
}

\author{
Nekrasov I. I., Fedulov A. A., Karamyshev A. P., \\ Parshin V. S., Dronov A. I., Khorev V. A. \\ Ural Federal University, 620002, 19 Mira Street, Yekaterinburg, Russia \\ artem. feduloffeyandex.ru
}

\begin{abstract}
The article considers DEFORM software package as a useful tool to model metalforming processes on the example of the outer upset and the radial forging processes. The specific features of these processes simulation have been described. Results obtained by simulation that can be used to implement the developed processes in the existing working technologies are listed.

Keywords-mathematical model, simulation, FEM, boundary conditions, outer upset, radial forging, pipe industry
\end{abstract}

\section{INTRODUCTION}

Modeling of hot deformation processes during metal-forming could be difficult to carry out because of presence of time-varying boundary conditions, a change in flow stress of metal subjected to deformation, etc. The most effective way to define such process parameters is to use software package based on FEM [1].

A researcher should execute a series of preprocessor steps and on each of them solve problems concerning the choice of the rational FE meshing, the appropriate type of FE, objects behavior and interactions between them in the designed scheme and also the proper choice of the solver and the iteration method for FE equation, etc.

Nowadays available software systems designed for metal-forming problems cover the entire class of problems for deformation and heat transfer during a simulation which allows defining the final shape of the workpiece, the stress-strain state of the metal in the deformation zone and loadstroke parameters of the deformation process $[2,3,4]$.

Only representation of a problem as a complex object consisted of several massive operations, which require a large amount of calculations, allows to obtain the most reliable result that would be relevant in the real industry. 


\section{THE DESIGN OF METAL-FORMING PROCESSES}

Studies conducted at the Department of Metallurgical and Rotary Machines (UrFU, Yekaterinburg, Russia) touch upon the modeling of such hot deformation processes as the radial forging of solid and hollow billets and the outer upset of tubing pipe ends. Both processes are relevant in the pipe industry. The main principles of metal-forming theory were used in each simulation [5].

\section{A. The radial forging of solid and hollow billets}

The radial forging process is used as a primary operation for the manufacturing of high consumer quality products or as a secondary preparatory operation in the areas of cold-drawn pipes. The reduction of the pipe diameter achieved in this process allows installation of the pipe in the line of drawing mill and its subsequent capture in the process of drawing.

The deformation occurs between dies of the radial-forging machine which movement is handled on fixed radius arcs according to the kinematics of selected machine. Depending on the mutual alignment of a feeding device and forging dies there are different schemes of a billet deformation (Fig. 1, 2).

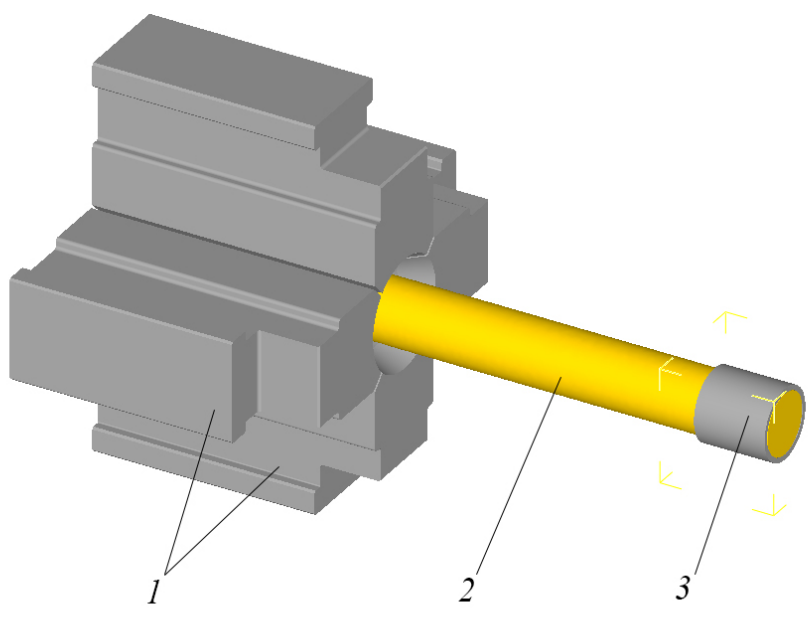

Figure 1: The scheme of the radial forging process with the longitudinal feeding ( 1 - forging dies; 2 - the billet; 3 - the object for a feeding device)

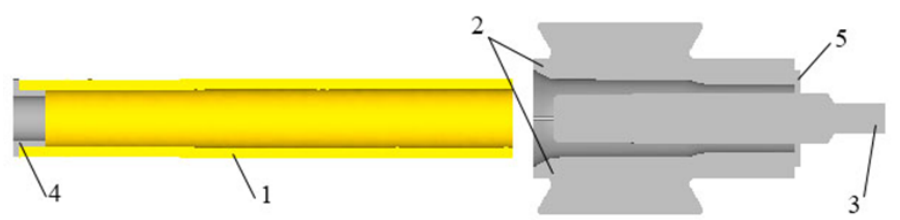

Figure 2: The scheme of the radial forging process with the cross-slide feeding ( 1 - the billet; 2 - forging dies; 3 - the mandrel;

4 - the object for a feeding device; 5 - thrust collar) 
In each case the die pass formed different shapes of a longitudinal section and a cross-section of the product. In modeling of preparatory operation round, figure-of-eight and trefoil-type shapes of the forged pipe end cross-section were considered [6]. The forging was achieved by one stage without a preliminary heating of corrosion-resistant pipe billet. At the same time a consumption of the part of boundary friction forces on temperature increases was taken into account (Fig. 3).

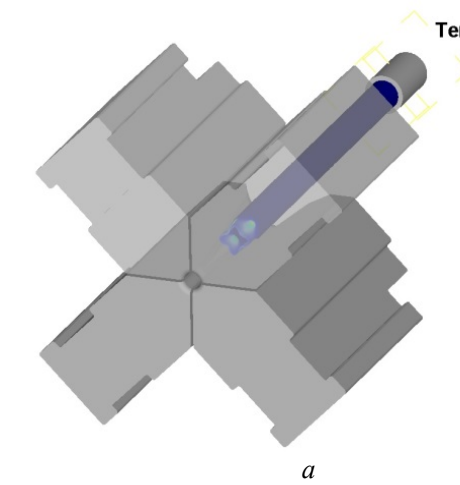

Temperature (C)
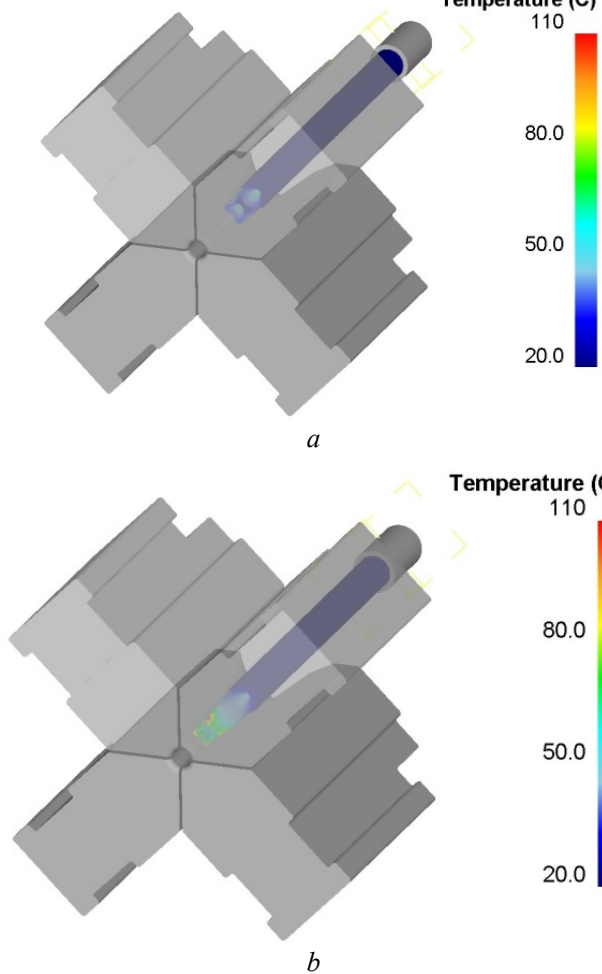

Temperature (C)

110

80.0

50.0

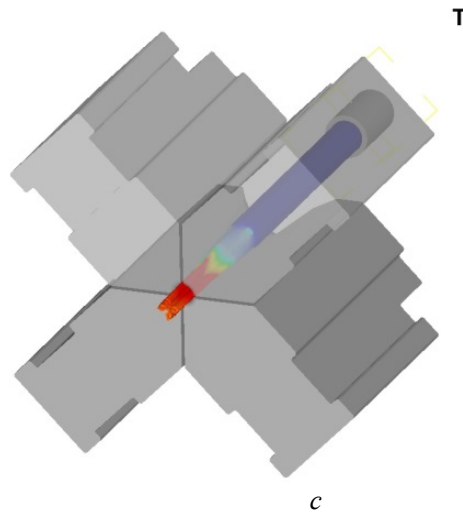

Temperature (C)

110

80.0

50.0

Figure 3: Temperature distributions in the billet at different times of the radial-forging process $(\mathrm{a}$ - beginning of the reduction; $\mathrm{b}$ - intermediate state;

$\mathrm{c}$ - ending with fully-formed pipe end) 
In modeling of the forging of semi-finished product for a subsequent machining the process was simulated as multi-staged with a preliminary heating of the billet for calculated length before the deformation and the cooling of metal between stages [7].

Moreover, in both cases the feeding of the billet was set so that it could describe a seizure of the forged piece by dies at each strike with simultaneous slippage in the feeding device.

The feature of the simulation is also in a large amount of strikes per minute that takes place in the forging machine and therefore results in instantly changes of stress-strain state of metal and should be considered in simulation controls.

\section{B. The outer upset of pipe ends}

The outer upset of pipe ends is one of stages of manufacturing of tubing and drilling pipes applied in gas and oil production. The technology includes operations of the pipe end heating, the feeding to upset press, the rear pipe end clamping in the sectional matrix with the subsequent upset in inner cavity of the matrix by the die movement (Fig. 4).

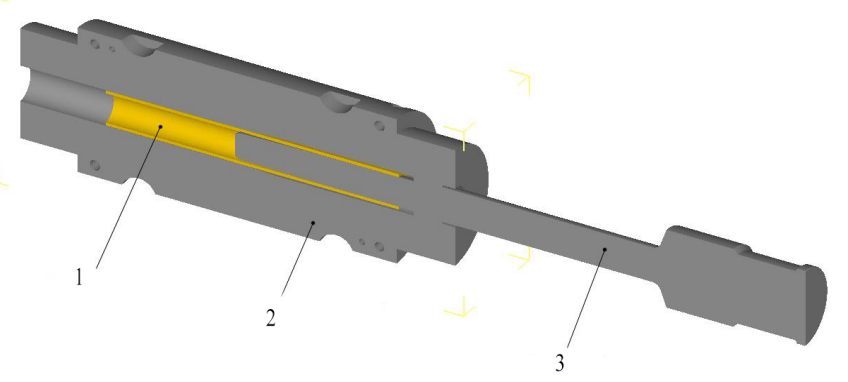

Figure 4: The scheme of the outer upset of tubing pipe ends process ( 1 - the billet; 2 - the sectional matrix; 3 - the die)

In the simulation of this process operations of the pipe end heating in the inductor, the air cooling of the pipe during the feeding to the axis of the press, the deformation in the press with temperature changing as a result of a contact between dies and the pipe and also the withdrawal of the die after the upset should be properly depicted.

The design of the model of hot deformation of the pipe end requires to input "flow stress strain", "flow stress - strain rate" and "flow stress - temperature" diagrams for a pipe object material in the preprocessor. Several curves were plotted for special chrome-nickel steels, data for which was obtained experimentally in laboratory tests [8] because data were absent in the reference literature.

Also for more precise analysis of the pipe upset end forming the method of varied meshing of the object was applied. The area, which was situated closely to the inner surface of the pipe, was meshed denser than others in order to make the observation for a defect initiation possible. The reason for most of defects is non-uniformity of the die motion or imperfect lubrication. 


\section{SOLUtion RESULtS}

Here discussed some of the data that was obtain by multistage problem definition.

For example, the front end of a pipe billet with a constant diameter and thickness has been heated in an inductor on a certain length to the temperature of $1250{ }^{\circ} \mathrm{C}$ for 50 seconds (fig. $5, a$ ), and cooled on air within 10 seconds during the transfer on the axis of the forging machine (fig 5 , $b$ ).

As seen, the temperature drop in the billet heated end is $80^{\circ} \mathrm{C}$, which would definitely affect the increase in a force necessary to fulfill deformation.

The usage of a mesh windows tool in a FE mesh generation during a deformation simulation allows not only to calculate the stress-strain state of a deformation zone with more accuracy but to predict the initiation of defects in a deformed object.

In fig. 6 the rod made from alloy AISI AL-2024 has been reduced with a strain of $60 \%$. At this value of strain an outlet of metal in a gap between dies could be seen, which could be modeled at an adequately small size of FE (application of fixed mesh windows in the deformation zone).

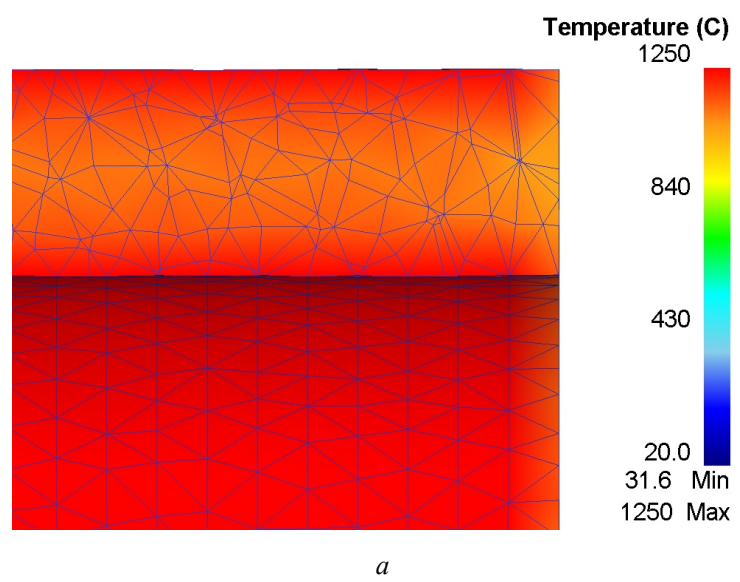




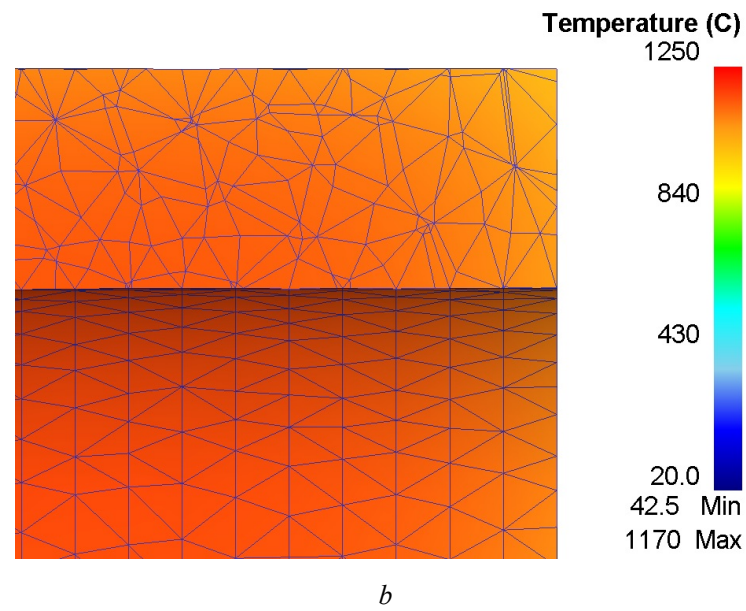

Figure 5: Temperature distributions in the billet ( $a$ - after the heating; $b$ - after the cooling)

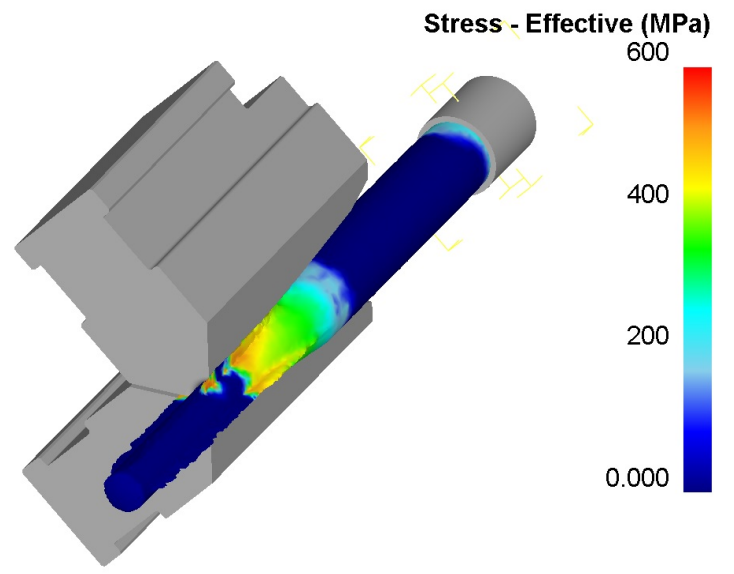

Figure 6: The radial forging process of a rod.

It should be mentioned that in real conditions the size of outlet would be significantly smaller due to a separation of metal from the billet in the shape of filings.

Fig. 7, 8 present the definition of the forces for the radial forging and the upset processes.

Using obtained values of parameters and its dependencies it is possible to perform necessary strength and dynamic calculations of the existing or developed equipment for the metal-forming technologies. 


\section{EXPERIMENTAL VALIDATION OF SIMULATION}

Authors carried out a series of experimental works to investigate above-mentioned processes and verify results of designed models.

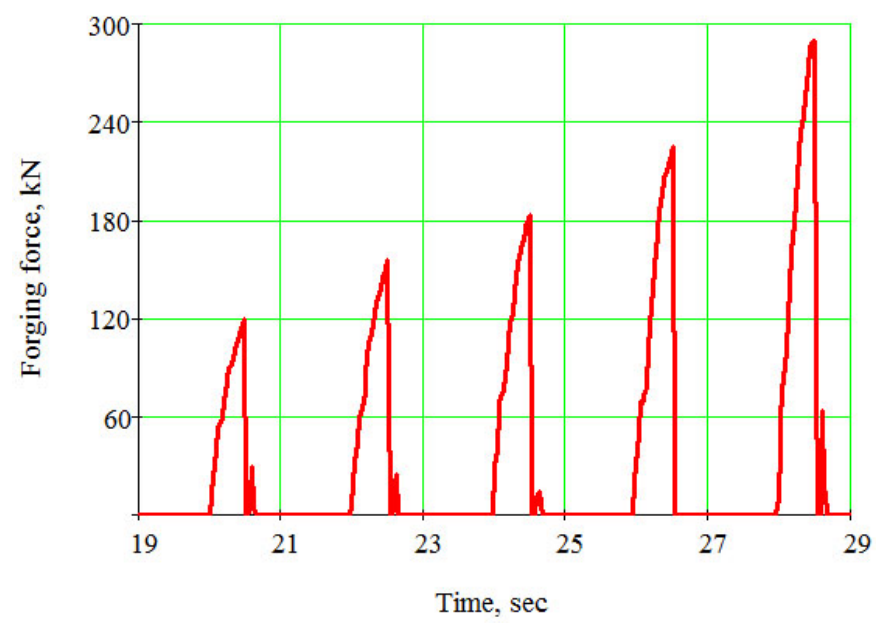

Figure 7: The forging load characteristic graph.

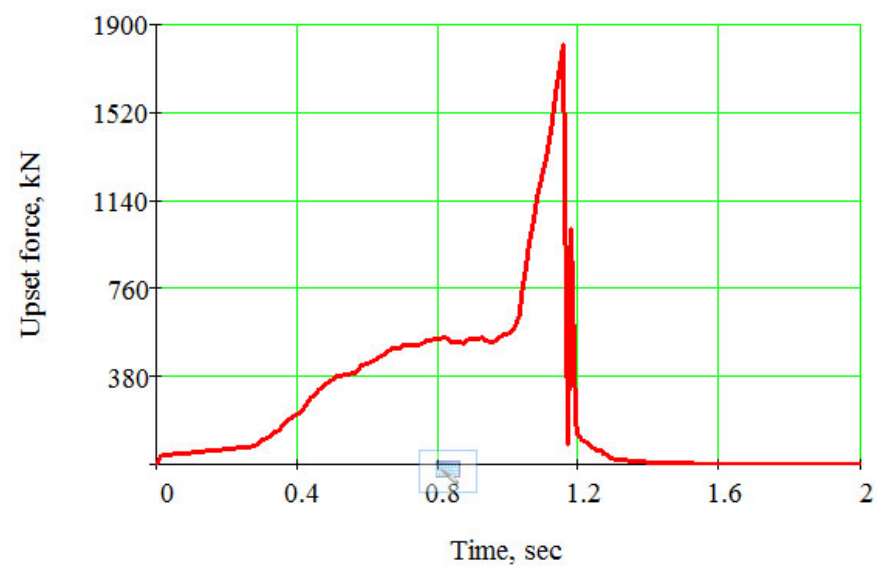

Figure 8: The upset load characteristic graph.

In order to validate adequacy of the pipe ends outer upset process simulation a determination of upset loads on the SMS Meer press were conducted by measuring pressure in the main cylinder at the end of the working stroke. Deviation between numerical and experimental data about 3.8\% testifies that the designed upset process model correct and in agreement with the real pipe end upset process. 
Also the experimental research was carried out for AISI AL-2024 samples forged with different values of reduction to investigate the damage of the material. Based on application of the hydrostatic weighing method and also conducted fractographic investigations of samples fractures, conclusion has been made that at high values of strain healing of defects occurs and density of a sample approaches to the one in an initial billet. At the same time the obtained numerical value of the stress state index, which primarily depends on the value and the character of mean stress and therefore the value of the damage, is in close relation with the experiment.

\section{CONCLUSIONS}

The definition of a problem in case of a multistage hot deformation process should be complex and divided into separate operations.

Results of conducted study on processes of the outer upset and the radial forging could be successfully applied in the developement of these processes in production.

\section{REFERENCES}

[1] Kobayashi S., Oh S.-I., Altan T. Metal forming and the finite-element // Oxford University press, Inc., 1989. - 377 p.

[2] Prakticheskoe rukovodstvo k programmnomu kompleksu DEFORM-3D: uchebnoe posobie / V.S. Parshin, A.P. Karami'shev, I.I. Nekrasov, A.I. Pugin, A.A. Fedulov. - Ekaterinburg: UrFU, 2010. - 266 s. (rus)

[3] Altinbalik T., Bingol S., Ayer O. Simulation of Lateral Extrusion of Spline Form Based on the Software DEFORM-3D // Applied Mechanics \& Materials. - Vol. 729. - 2014. - PP. 149-154.

[4] Bassan F., Ferro P., Bonollo F. Prediction of defects in multistage cold forging by using finite element method // Key Engineering Materials. - Vol. 622-623. - 2014. - PP. 659-663.

[5] Kim H., Sweeney K., Altan T. Application of computer aided simulation to investigate metal flow in selected forging operations // Journal of Materials Processing Technology. - Vol. 46. - 1994. - №1-2. - PP. 127-154.

[6] Karamyshev A. P, Nekrasov I. I., Parshin V. S., Pugin A. I., Fedulov A. A. Finding an efficient shape for the cross section of the front end of a tubular semifinished product to perform drawing // Metallurgist. - Vol. 55. - 2011. - №34. - PP. 274-277.

[7] Karamyshev A. P, Nekrasov I. I., Pugin A. I., Fedulov A. A. Modelling of the radial forging process of a hollow billet with the mandrel on the lever radial forging machine // IOP Conference Series: Materials Science and Engineering. 2016.

[8] Konovalov A.V., Smirnov A.S., Parshin V.S., Dronov A.I., Karamyshev A.P., Nekrasov I.I., Fedulov A.A., Serebryakov A.V. Study of the resistance of steels 18KHMFB and 18KH3MFB to hot deformation // Metallurgist. Vol. 59. - 2016. - №11-12. - PP. 1118-1121. 